Sādhanā Vol. 39, Part 2, April 2014, pp. 377-390. (C) Indian Academy of Sciences

\title{
Transaction charges allocation using sensitivity factor methodology
}

\author{
S CHARLES RAJA*, J JESLIN DRUSILA NESAMALAR \\ and P VENKATESH
}

Electrical and Electronics Engineering Department, Thiagarajar College of Engineering, Madurai, India

e-mail: charlesrajas@gmail.com

MS received 20 July 2012; revised 18 September 2013; accepted 27 September 2013

\begin{abstract}
Deregulation of the electricity industry aims for creating a competitive market to trade electricity, which generates a host of new technical challenges among market participants and power system researchers. One of the major challenges is to establish a cost for system services on a nondiscriminatory basis. In this paper, the evaluation of transmission cost is proposed based on sensitivity factor method like AC Power Transfer Distribution Factor (ACPTDF) method for bilateral and multilateral transactions. The transacted power is estimated by ACPTDF method for each transaction. The advantages of the proposed methodology are demonstrated on a sample 6 bus, IEEE 30 bus and Indian Utility 69 bus systems. The solution provides a better pricing approach that can impact a more reasonable economic indicator for transmission cost.
\end{abstract}

Keywords. Deregulation; transmission pricing; AC power transfer distribution factor (ACPTDF); bilateral transaction; multilateral transaction

\section{Introduction}

Deregulation has revolutionized the back-bone of the country's economy in the fields like transportation, communication, aviation and so in power sector (NERC 1997). It is different from liberalization, where more players enter the market but maintain the regulation and guarantee of consumer rights, maximum and minimum prices. Electricity restructuring aims at creating competitive markets to trade electricity. Here, customers have the option to purchase energy from different sources (Christie et al 2000). For the implementation of power transfer between different buyers and sellers, efficient transmission cost allocation need to be considered as per their extent of use. With the current thrust towards a competitive generation market with new independent entrants, the 'correct' pricing of electric power transmission service is crucial in providing signal to the marketplace for efficient short-run operation and long-term capital investments (Willis et al 1996). Regulation in the transmission system should cover the following issues:

*For correspondence 
transmission expansion planning, connection of new agents, recovery of capital investment and tariff structure. Under this framework, the transmission tariff charged for the customers becomes an important parameter because it can be considered as the control variable in the electricity system (Shirmohmmadi et al 1991).

Bialek (1997) presented a novel, topological approach, which determines the share, as opposed to the impact of a particular generator or load in every line flow, which is based on electrical tracing method. Ni et al (2000) applied graph theory to solve the problem of power flow tracing with the proof of two lemmas to show the feasible condition for the suggested method, which is also complex in procedure. Kirschen et al (1997) presented another approach, which introduces new concepts such as domain, common, link and state graph. But there is no clear declaration and proof of the conditions required for this method. Ashwani \& Srivastava (2002) and Manikandan et al (2008) used AC Power Transfer Distribution Factor (ACPTDF) method for available transfer capability calculation.

This paper proposes a new approach, simple and non iterative, for allocating transmission transaction charges among users in transmission services for various contracts. The change in power flow due to each transaction is calculated based on a sensitivity factor called (ACPTDF) and the transmission tariff has been calculated based on it. In MW-mile method, the change in power flow is determined by running load flow program repeatedly. But, in the proposed method, the change in line power flow is directly computed without re-running load flow program. This reduces the complexity in calculation and reduces the pace. The overall transaction charges are determined on sample six bus, IEEE 30 bus and Indian Utility 69 bus systems by utilizing MW-mile method concept.

\section{Transmission pricing methods}

Transmission pricing is the cost of transferring power between any two nodes on the transmission network. Wheeling occurs when a transmission-owning utility allows another utility or independent power producer to move (or wheel) power over its transmission lines. The basic transmission pricing methods in the deregulated power system are Postage Stamp Pricing Method, Contract Path Pricing Model, MW-Mile Pricing Method and Unused Transmission Capacity Pricing Method.

In Postage Stamp Pricing Method, based on average system costs, a flat per $\mathrm{kW}$ charge for network access within a particular zone is being charged. It creates higher costs above marginal costs because it incorporates historical fixed costs. The cost for transmitting power within the zone is independent of the transmission distance. Though this method provides a way to recover the fixed costs of the network, they provide no information about congestion. The advantage of using this method is that it is easy to administer.

Contract Path Pricing calls for transmission from a point to another point based on the cost of single identified path. The price includes a capacity charge to cover the capital costs, and energy charges are based on losses and other operating costs. Suppose two parties want to move power between two points, and choose a transmission line as 'contract path' between the two points, then even knowing that the power will actually move on different parallel paths between the two stations, they calculate the cost to be paid based on this 'contract path'.

In MW-Mile pricing method, the tariff explicitly reflects the fact that the cost of transmission depends on the distance through which the power is transmitted and the quantum of power transmission. MW-Mile pricing involves repeated load flow analysis to model the power flow on the transmission network to determine transmission charge. The distance and power flow, 
if computed correctly, reflect the impact of a transmission arrangement on the system more accurately. The cost of transmission per megawatt-mile is the total cost averaged over megawattmile of usage.

$$
T C_{t}=\sum_{l=1}^{n r} \frac{L_{l} F_{l} \Delta P_{l}^{t}}{\sum_{l=1}^{n r} P_{l}}
$$

where,

$T C_{t}$ is the transmission pricing for transaction $t$ in $\$ / \mathrm{MW}-\mathrm{h}$.

$L_{l}$ is the length of the line $l$ in p.u.

$F_{l}$ is the cost of power in line $l$ in $\$ / \mathrm{MW}$-h.

$\Delta P_{l}^{t}$ is the change in power flow in line $l$ due to transaction $t$ in MW.

$P_{l}$ is the sum of power flow in line $l$ due to all transactions in MW.

$n r$ is the total number of lines in a system.

Unused Transmission Capacity Pricing method revises the MW-mile formulation by charging the transmission users based on the percentage utilization of the facility, instead of the sum of flows contributed by all the users. That is, transmission users will be charged only for the actual capacity use but not for the unscheduled capacity.

$$
T C_{t}=\sum_{l \in n r} C_{l} \frac{\left|F_{l}^{t}\right|}{\overline{F_{l}}},
$$

where,

$C_{l}$ is the embedded cost of facility $l$ in $\$ / \mathrm{MW}-\mathrm{h}$.

$\left|F_{l}^{t}\right|$ is the magnitude of flow on facility $l$ caused by transaction $t$ in MW.

$\overline{F_{l}}$ is the facility capacity in MW.

But this revised formulation cannot get full recovery of the fixed transmission cost, since the net flow is usually smaller than the actual capacity under normal system condition.

\section{Transmission usage evaluation}

Accurate knowledge of transmission usage is essentially important in the implementation of usage based cost allocation method. On one hand, due to the nonlinear nature of power flow equations, it is theoretically very difficult to decompose the network flow into components associated with individual customers. On the other hand, from an engineering point of view, it is possible and acceptable to apply approximate model or sensitivity indices to estimate the contribution for the network flow from individual user.

\subsection{Distribution factor}

During transmission pricing, the MW flow must be allocated to each line or group of lines in proportion to the MW being transmitted by each transaction. This is accomplished through the use of the linear Power Transfer Distribution Factor (PTDF). A transaction is a specific amount of power that is injected into the system at one bus by a generator and extracted at another bus by a load. The coefficient of linear relationship between the amount of transaction and flow on a line is called PTDF. PTDF is also called sensitivity factor because it relates how much a line 
is sensitive for a change in transaction amount. The PTDF is the fraction of the amount of a transaction from one bus to another that flows over a given transmission line.

PTDFs determine the linear impact of power transfer (or change in power injection) on the elements of power system. These values provide a linearized approximation of the effect of flow on transmission lines and interfaces, in response to the transaction between seller and buyer.

\subsection{ACPTDF formulation}

The sensitivity factor ACPTDF is used to find various transmission system quantities for a change in MW transaction at different operating conditions by utilizing the sensitivity property of Newton Raphson Load Flow Jacobian Matrix.

Consider a bilateral transaction $P_{t}$ between seller bus $m$ and buyer bus $n$. Further, consider a line $l$ which carries the part of the transacted power and is connected between buses $i$ and $j$. For a change in real power transaction between the above buyer and seller, say by $\Delta P_{t-m n} \mathrm{MW}$, the corresponding change in transmission line quantity is $\Delta P_{i j} \mathrm{MW}$, and the ACPTDF can be defined as

$$
\mathrm{ACPTDF}_{i j, m n}=\frac{\Delta P_{i j}}{\Delta P_{t-m n}} .
$$

The transmission quantity can be either real power flow from bus $i$ to $j\left(P_{i j}\right)$ (or) real power flow from bus $j$ to $i\left(P_{j i}\right)$. Consider full Jacobian in polar coordinates $[J]$, the equation can be written as

$$
\left(\begin{array}{c}
\Delta \delta \\
\Delta V
\end{array}\right)=(J)^{-1}\left(\begin{array}{c}
\Delta P \\
\Delta Q
\end{array}\right)
$$

Consider a system, which has $n$ number of buses, $n g$ number of generator buses and $n l$ number of load buses. Bus 1 is taken as slack bus. A transaction is defined by a 4 tuple $\left(t, m, n, P_{t}\right)$ where $t$ is the transaction number, $m$ and $n$ are the source and sink nodes and $P_{t}$ is the power transacted in MW.

Eq. (4) can be expanded as,

$$
\left(\begin{array}{c}
\Delta \delta_{2} \\
: \\
: \\
: \\
\Delta \delta_{n} \\
\Delta V_{n g+1} \\
\vdots \\
: \\
: \\
\Delta V_{n g+n l}
\end{array}\right)=(J)^{-1}\left(\begin{array}{c}
\Delta P_{2} \\
: \\
: \\
: \\
\Delta P_{n} \\
\Delta Q_{n g+1} \\
\vdots \\
\vdots \\
\Delta Q_{n g+n l}
\end{array}\right)
$$

where $J$ is load flow Jacobian.

In a base case load flow, if only one bilateral transaction is considered by an amount of $\Delta P_{t}$ MW, only the following two entries in the mismatch vector on RHS of Eq. (5) will be non zero. For a new power transaction number $t$,

$$
\begin{array}{cl}
\Delta P_{m}=+P_{t} ; & \Delta P_{n}=-P_{t}, \\
\Delta P_{k}=0 ; & \Delta Q=0,
\end{array}
$$

where $(k=2, \ldots \ldots, n ; \neq m, n)$. 
The change in power flow for an arbitrary line $i-j$ can be evaluated by sensitivity analysis as follows.

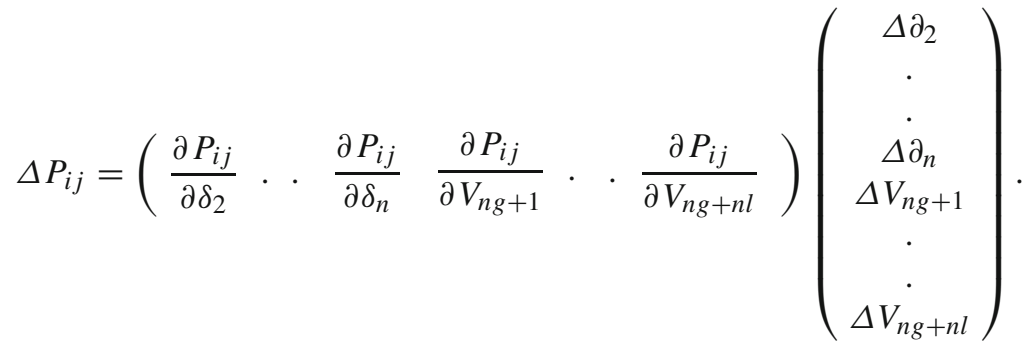

Substituting Eq. (6) in RHS of Eq. (5) and by incorporating it in Eq. (7), we have $\Delta P_{i j}$ in MW,

$$
\Delta P_{i j}=\left(\frac{\partial P_{i j}}{\partial \delta_{2}} \cdot \frac{\partial P_{i j}}{\partial \delta_{n}} \frac{\partial P_{i j}}{\partial V_{n g+1}} \cdot \frac{\partial P_{i j}}{\partial V_{n g+n l}}\right)(J)^{-1}\left(\begin{array}{c}
P_{t} \\
\cdot \\
\cdot \\
-P_{t} \\
0 \\
\cdot \\
\cdot \\
0
\end{array}\right) .
$$

Eq. (8) can be written as:

$$
\Delta P_{i j}=\mathrm{ACPTDF}_{i j, m n} \Delta P_{t},
$$

where $\Delta P_{t}$ is $\left(\begin{array}{lllllll}P_{t} & \ldots & -P_{t} & 0 & . & 0\end{array}\right)^{T}$ in MW and is calculated using Eq. (6). ACPTDF is the matrix multiplication of $\left(\frac{\partial P_{i j}}{\partial \delta_{2}} \cdot \frac{\partial P_{i j}}{\partial \delta_{n}} \frac{\partial P_{i j}}{\partial V_{n g+1}} \cdot \frac{\partial P_{i j}}{\partial V_{n g+n l}}\right)$ and Jacobian inverse $(J)^{-1}$.

With the mismatch vector elements, the change in voltage angle and magnitude at all the buses can be computed from Eq. (5) and, hence the new voltage profile can be calculated. These can be utilized to compute the changes in the transmission quantities from the base case. Once $\Delta P_{i j}$ of all the lines corresponding to a transaction $\Delta P_{t}$ is known, ACPTDFs can be obtained from Eq. (9).

These ACPTDFs, which are computed at a base load flow condition, have been utilized for computing change in transmission quantities at other operating conditions as well. The ACPTDF values are also calculated for multilateral transaction in which a group of sellers have a bilateral contract with a group of buyers. The change in the multilateral transaction can be assumed to be shared equally by each of the sellers and the buyers. However, the transaction amount can be shared in any pre-decided ratio in a deregulated market. The mismatch vector for the multilateral transaction will have non zero entries corresponding to the buyer and seller buses. The rest of the procedure for calculation of ACPTDF will be the same as outlined above for the bilateral transaction case.

\subsection{Proposed pricing method}

The proposed method is used to calculate the charges for the transacted power based on the magnitude of transacted power determined by ACPTDF and the distance between the entry and 
exit. The process of the proposed method is given in Appendix A. The proposed formula for total cost $\left(T C_{t}\right)$ due to bilateral transaction $t$ between bus $m$ and $n$ by incorporating ACPTDF is:

$$
T C_{t}=\sum_{l=1}^{n r} \frac{C_{l}^{*} L_{l}^{*} \mathrm{ACPTDF}_{l, t}^{*} \Delta P_{t}}{\sum_{l=1}^{n r} P F_{l}}
$$

where,

$C_{l}$ is the cost of line $l$ in $\$ / \mathrm{MW}-\mathrm{h}$.

$L_{l}$ is the length of line $l$ in p.u.

$n r$ is the total number of lines.

$P F_{l}$ is the sum of absolute power flow caused by all the power contracts in MW.

$\mathrm{ACPTDF}_{l, t}$ is AC Power Transfer Distribution Factor on the line $l$ due to transaction $t$ between buses $m$ and $n$. For the direct or reverse power flows, the magnitude of ACPTDF is considered as positive.

\section{Algorithm}

STEP 1. Read system input data.

STEP 2. Run Newton Raphson Load Flow for base case operation.

STEP 3. Consider wheeling transactions $\left(\mathrm{t}_{k}\right)$.

STEP 4. Compute ACPTDFs using Eq. (9).

STEP 5. Take transaction as variable and compute the feasible wheeling transactions.

STEP 6. Dispatch the possible transactions and determine the total cost of the transaction using Eq. (10).

STEP 7. Print the total transaction cost.

STEP 8. If any other transaction is to be carried out, consider the next transaction and go to step 4.

\section{Results and discussion}

The transmission charges using ACPTDF method are calculated on sample 6 bus, IEEE 30 bus and Indian utility 69 bus systems by considering bilateral and multilateral transactions. The simulation studies are carried out on Intel Pentium Dual Core, $2.40 \mathrm{GHz}$ system in MATLAB 7.3 environment.

\subsection{Sample 6 bus system}

The numerical data for the sample 6 bus system is taken from (Wood \& Wollenberg 1996). The line data is given in appendix B. This system consists of three generator buses and three load buses with a total demand of $210 \mathrm{MW}$. The first bus is considered as slack bus. To simplify the calculation, the charge for the use of a particular line (in per-unit) is assumed to be equal to the line resistance.

In this test system, three different bilateral transactions are carried out such as $\mathrm{T}(1,1,6,10)$, $\mathrm{T}(2,2,5,25)$, and $\mathrm{T}(3,3,6,50)$. Also, various magnitude of transacted power are considered in the first transaction as $\mathrm{T}(1,1,6,10), \mathrm{T}(1,1,6,20)$ and $\mathrm{T}(1,1,6,30)$. In this 4 tuple model 
Table 1. Line power flow impacts in MW for 1-6 transaction.

\begin{tabular}{|c|c|c|c|c|c|c|c|}
\hline \multirow{2}{*}{$\begin{array}{l}\text { Transaction } \\
\text { lines }\end{array}$} & \multirow{2}{*}{$\begin{array}{c}\text { ACPTDF } \\
\text { values }\end{array}$} & \multicolumn{2}{|c|}{$\mathrm{T}(1,1,6,10)$} & \multicolumn{2}{|c|}{$\mathrm{T}(1,1,6,20)$} & \multicolumn{2}{|c|}{$\mathrm{T}(1,1,6,30)$} \\
\hline & & $\begin{array}{l}\text { ACPTDF } \\
\text { method }\end{array}$ & $\begin{array}{c}\text { RPF } \\
\text { method }\end{array}$ & $\begin{array}{l}\text { ACPTDF } \\
\text { method }\end{array}$ & $\begin{array}{c}\text { RPF } \\
\text { method }\end{array}$ & $\begin{array}{l}\text { ACPTDF } \\
\text { method }\end{array}$ & $\begin{array}{c}\text { RPF } \\
\text { method }\end{array}$ \\
\hline$\overline{1-2}$ & 0.4268 & 4.2681 & 4.2998 & 8.5362 & 8.6643 & 12.804 & 13.095 \\
\hline $1-4$ & 0.3243 & 3.2425 & 3.2635 & 6.4851 & 6.5697 & 9.7276 & 9.9197 \\
\hline $1-5$ & 0.3239 & 3.2386 & 3.2555 & 6.4772 & 6.5453 & 9.7158 & 9.8696 \\
\hline $2-3$ & 0.2153 & 2.1534 & 2.1604 & 4.3068 & 4.3353 & 6.4602 & 6.5254 \\
\hline $2-4$ & -0.2465 & -2.4649 & -2.4723 & -4.9298 & -4.9597 & -7.3947 & -7.4626 \\
\hline $2-5$ & 0.0162 & 0.1615 & 0.1617 & 0.3230 & 0.3239 & 0.4845 & 0.4865 \\
\hline $2-6$ & 0.4153 & 4.1527 & 4.1635 & 8.3055 & 8.3488 & 12.458 & 12.556 \\
\hline $3-5$ & -0.1483 & -1.4828 & -1.4836 & -2.9657 & -2.9686 & -4.4485 & -4.4549 \\
\hline $3-6$ & 0.3627 & 3.6272 & 3.6328 & 7.2544 & 7.2771 & 10.881 & 10.933 \\
\hline $4-5$ & 0.0977 & 0.9771 & 0.7018 & 1.9541 & 1.4107 & 2.9312 & 2.1267 \\
\hline $5-6$ & 0.2107 & 2.1065 & 2.4572 & 4.2131 & 4.9249 & 6.3196 & 7.4030 \\
\hline
\end{tabular}

$\mathrm{T}(1,1,6,10)$, first position represents the transaction number, second position represents seller bus number, third position represents buyer bus number and amount of power contract is indicated in fourth position.

The impact of power contracts for each line is given in table 1 . The main advantage of the proposed method is for different quantity of power transfer for a single transaction, the ACPTDF need not be calculated repeatedly but the amount of transaction can be considered as a scalar and is sufficient to be multiplied with ACPTDF values. For 1-6 transaction, three different amount of power such as 10,20 and $30 \mathrm{MW}$ have been considered and power flow impact is determined by multiplying the corresponding amount with ACPTDF values. The sensitivity of lines calculated by ACPTDF method give the same results as Repeated Power Flow (RPF) method.

The power flow impact for various transactions is given in table 2 . These impacts are predicted without running the load flow repeatedly using ACPTDF method, whereas in RPF method, Newton Raphson (NR) program has to be run repeatedly for each power contract. In $\mathrm{T}(1,1,6,10)$, the high power impact is identified as 4.268 MW in the line 1-2 by ACPTDF and 4.299 MW by

Table 2. Impacts on line power flows in MW for power transactions.

\begin{tabular}{|c|c|c|c|c|c|c|}
\hline \multirow{2}{*}{$\begin{array}{l}\text { Transaction } \\
\text { lines }\end{array}$} & \multicolumn{2}{|c|}{$\mathrm{T}(1,1,6,10)$} & \multicolumn{2}{|c|}{$\mathrm{T}(2,2,5,25)$} & \multicolumn{2}{|c|}{$\mathrm{T}(3,3,6,50)$} \\
\hline & $\begin{array}{l}\text { ACPTDF } \\
\text { method }\end{array}$ & $\begin{array}{c}\text { RPF } \\
\text { method }\end{array}$ & $\begin{array}{l}\text { ACPTDF } \\
\text { method }\end{array}$ & $\begin{array}{c}\text { RPF } \\
\text { method }\end{array}$ & $\begin{array}{l}\text { ACPTDF } \\
\text { method }\end{array}$ & $\begin{array}{c}\text { RPF } \\
\text { method }\end{array}$ \\
\hline $1-2$ & 4.268 & 4.299 & -3.353 & -3.266 & 0.671 & 0.806 \\
\hline $1-4$ & 3.242 & 3.263 & -0.958 & -0.888 & 0.457 & 0.563 \\
\hline $1-5$ & 3.238 & 3.255 & 5.203 & 5.281 & 0.169 & 0.278 \\
\hline $2-3$ & 2.153 & 2.160 & 4.525 & 4.558 & -7.668 & -7.601 \\
\hline $2-4$ & -2.464 & -2.472 & 4.890 & 4.869 & -0.370 & -0.445 \\
\hline $2-5$ & 0.161 & 0.161 & 7.577 & 7.603 & -0.187 & -0.177 \\
\hline $2-6$ & 4.152 & 4.163 & 4.860 & 4.893 & 8.849 & 8.980 \\
\hline $3-5$ & -1.482 & -1.483 & 4.972 & 5.00 & 5.869 & 5.862 \\
\hline $3-6$ & 3.627 & 3.632 & -0.465 & -0.470 & 36.51 & 36.54 \\
\hline $4-5$ & 0.977 & 0.701 & 2.553 & 3.882 & -0.283 & 0.082 \\
\hline $5-6$ & 2.106 & 2.457 & -3.617 & -4.212 & 3.616 & 5.793 \\
\hline
\end{tabular}


Table 3. Costs to be recovered from each line for each contract (\$/MW-h).

\begin{tabular}{|c|c|c|c|c|c|c|}
\hline \multirow{2}{*}{$\begin{array}{l}\text { Transaction } \\
\text { lines }\end{array}$} & \multicolumn{2}{|c|}{$\mathrm{T}(1,1,6,10)$} & \multicolumn{2}{|c|}{$\mathrm{T}(2,2,5,25)$} & \multicolumn{2}{|c|}{$\mathrm{T}(3,3,6,50)$} \\
\hline & $\begin{array}{c}\text { ACPTDF } \\
\text { method }\end{array}$ & $\begin{array}{c}\text { RPF } \\
\text { method }\end{array}$ & $\begin{array}{l}\text { ACPTDF } \\
\text { method }\end{array}$ & $\begin{array}{c}\text { RPF } \\
\text { method }\end{array}$ & $\begin{array}{l}\text { ACPTDF } \\
\text { method }\end{array}$ & $\begin{array}{c}\text { RPF } \\
\text { method }\end{array}$ \\
\hline $1-2$ & 5.147 & 5.136 & 4.044 & 3.902 & 0.809 & 0.963 \\
\hline $1-4$ & 3.481 & 3.461 & 1.029 & 0.942 & 0.491 & 0.597 \\
\hline $1-5$ & 3.009 & 2.954 & 4.834 & 4.793 & 0.157 & 0.252 \\
\hline $2-3$ & 0.750 & 0.754 & 1.577 & 1.592 & 2.673 & 2.654 \\
\hline $2-4$ & 1.595 & 1.587 & 3.165 & 3.127 & 0.240 & 0.286 \\
\hline $2-5$ & 0.203 & 0.203 & 9.561 & 9.574 & 0.236 & 0.223 \\
\hline $2-6$ & 1.627 & 1.616 & 1.905 & 1.899 & 3.468 & 3.485 \\
\hline $3-5$ & 1.443 & 1.442 & 4.842 & 4.860 & 5.715 & 5.698 \\
\hline $3-6$ & 0.179 & 0.179 & 0.023 & 0.023 & 1.798 & 1.798 \\
\hline $4-5$ & 5.125 & 3.005 & 13.39 & 16.64 & 1.484 & 0.352 \\
\hline $5-6$ & 2.255 & 1.972 & 3.873 & 3.380 & 3.872 & 4.649 \\
\hline
\end{tabular}

RPF method. Also, high impact in power flow for transaction $\mathrm{T}(2,2,5,25)$ has been identified in line $2-5$, whereas for transaction $\mathrm{T}(3,3,6,50)$, line 3-6 is identified as high sensitivity line. So, the high sensitivity line identified by both methods is the same and it is nearer to seller/buyer contract buses. The negative sign indicates that the actual power flow is in reverse direction.

The transaction cost recovered from each line is calculated for the above transactions based on ACPTDF method and MW-Mile method using (10) and (1). They are given in table 3. The results clearly indicate that, the cost allocated to each line by ACPTDF method is quite closer to the MW-Mile method. Though the line 3-6 has more impact during T $(3,3,6,50)$ transaction, the cost to be recovered from this line is only $1.798 \$ / \mathrm{MW}$-h. This is because of low transmission cost on line 3-6 compared to other lines.

The total transacted cost for each contract is shown in figure 1. For the transaction $\mathrm{T}(2,2$, $5,25)$, the allocated cost is 48.243 and $50.734 \$ / M W-h$ by the proposed ACPTDF method and MW-Mile method, respectively. Since the cost of lines $4-5 \& 2-5$ is high, the recovered cost from this line is higher than other lines for this transaction.

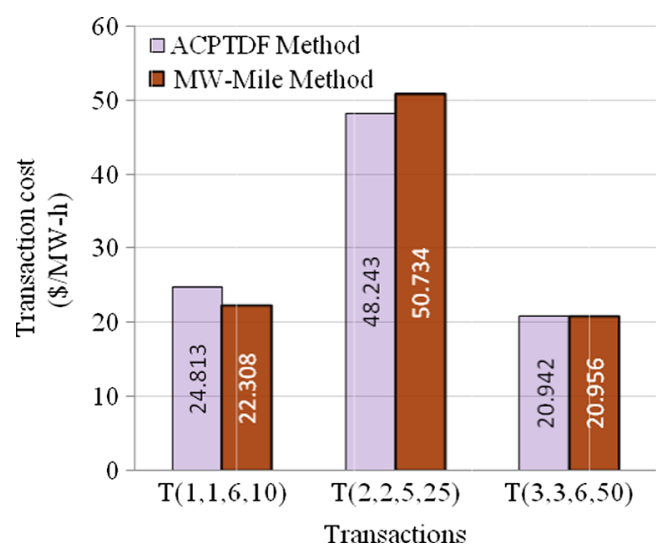

Figure 1. Total transacted cost for each contract. 


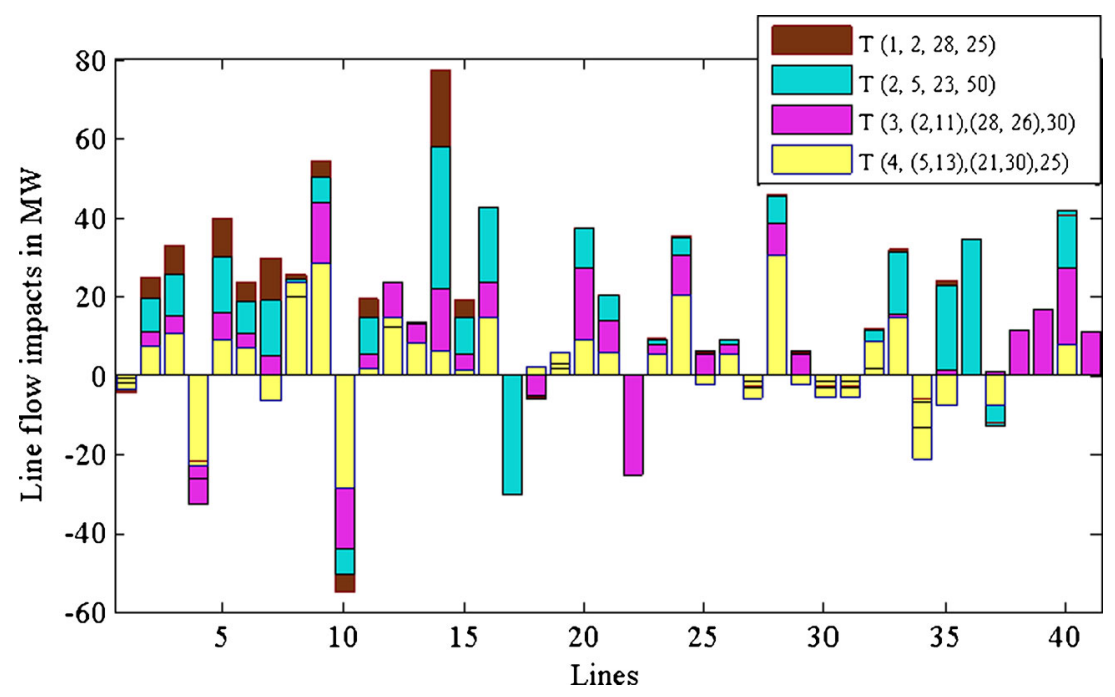

Figure 2. Impacts on line power flows in MW for power contracts.

\subsection{IEEE 30 bus system}

The numerical data for IEEE 30 bus system is taken from http://www.ee.washington.edu/ research/pstca. There are 6 generators and 24 loads with the total demand of $283.4 \mathrm{MW}$ in this system. Generator connected to bus 1 is considered as slack. To simplify the calculation, the charge for the use of a particular line (in per-unit) is assumed to be equal to the line resistance. The transaction transmission charges are calculated for the two bilateral transactions such as $\mathrm{T}$ $(1,2,28,25)$ and $\mathrm{T}(2,5,23,50)$ and two multilateral transactions such as $\mathrm{T}(3,\{2,11\},\{28$, $26\}, 30)$ and $\mathrm{T}(4,\{5,13\},\{21,30\}, 25)$.

The power impact on each line due to power contracts are shown in figure 2. For first transaction, the first fifteen lines are impacted more than other lines. It is clearly depicted in figure 2. This is because seller/buyer buses are situated nearer to these lines. So, for bilateral transactions, the power impact is more on lines connected nearer to buyer and seller buses. The power impacts are distributed along all lines for the two multilateral transactions, especially for the fourth transaction $\mathrm{T}(4,\{5,13\},\{21,30\}, 25)$.

The cost allocation for each line due to power contracts is shown in figure 3 . Since the amount of power transaction of second contract $\mathrm{T}(2,5,23,50)$ is $50 \mathrm{MW}$, the cost allocated to each line for this contract is higher than the first contract $\mathrm{T}(1,2,28,25)$. For the multilateral power contract $\mathrm{T}(3,\{2,11\},\{28,26\}, 30)$, the highest cost recovered is 25.87048 \$/MW-h by ACPTDF method and 25.43491 \$MW-h by MW-Mile method from the line $25-26$ ( $36^{\text {th }}$ line $)$. This is because, of the high power impact on line 25-26 during this contract. The total cost recovered from the line $25-26$ ( $36^{\text {th }}$ line) for all transactions is 46.69 \$/MW-h. It is the highest cost to be recovered in this system since it has more impact for all transactions. The transaction cost calculated by the proposed ACPTDF method and MW-Mile method are having similar pattern of results for the transaction considered. As there is less impact on power flow and low transmission cost in some transmission lines, the transaction cost allocated to these lines are very low $\left(13^{\text {th }}\right.$, $17^{\text {th }}$ lines). But in some cases, though lines are having high power impacts, the cost allocated is low due to low transmission cost for those corresponding lines $\left(8^{\text {th }}, 12^{\text {th }}, 18^{\text {th }}, 22^{\text {nd }}, 40^{\text {th }}\right.$ lines $)$. 


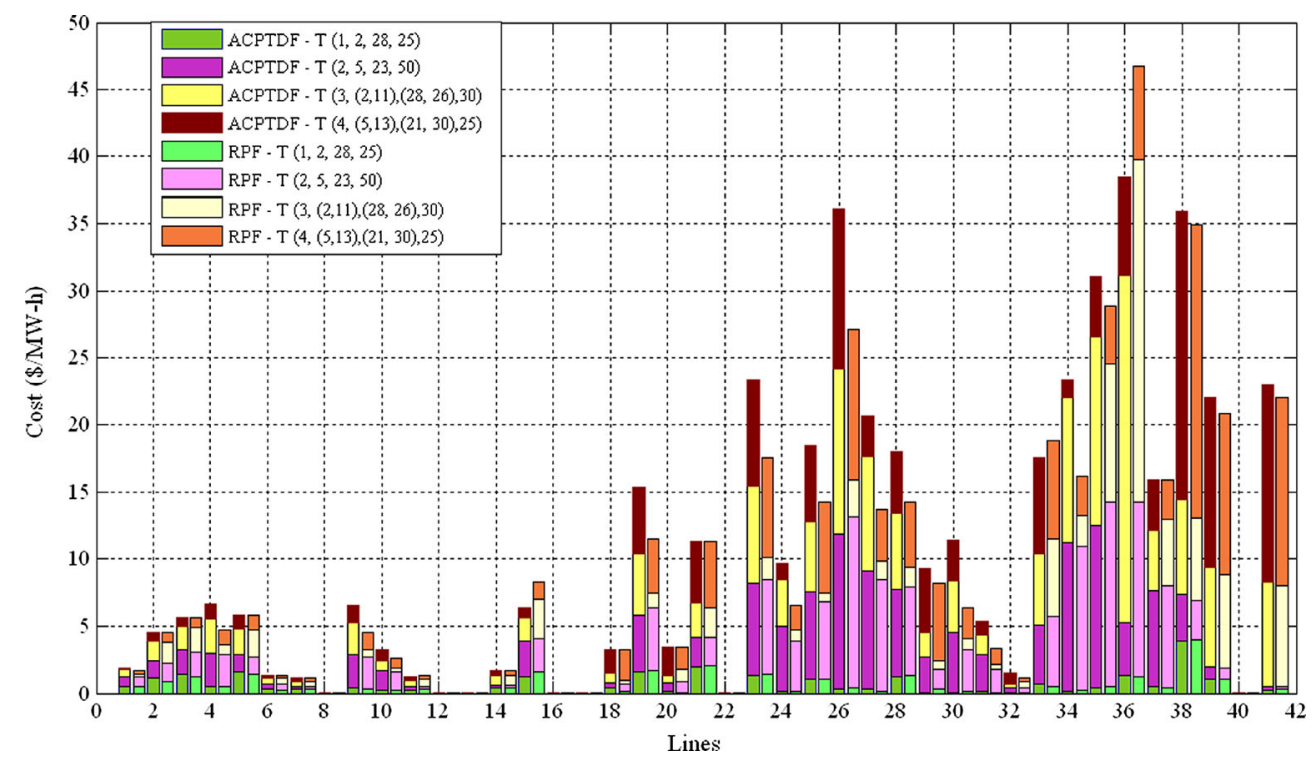

Figure 3. Costs to be recovered for each line - each contract (\$/MW-h).

The total transacted cost for each contract is given in table 4. The allocated cost for $\mathrm{T}(3,\{2,11\},\{28,26\}, 30)$ is 156.267 and 157.222 \$/MW-h by the proposed ACPTDF method and MW-Mile method, respectively. Due to more impact on high cost lines, the recovered cost of this contract is higher than other transaction considered. Since the power impact of first contract $\mathrm{T}(1,2,28,25)$ is very less, the cost of transaction is very low and it is assigned as 25.476 \$/MW-h.

\subsection{Indian utility 69 bus system}

The described utility system represents Tamil Nadu state power map. Tamil Nadu is one of the southern states of India and this system is under the control of Tamil Nadu Electricity Board (TNEB), a state government owned Power Corporation. The utility system has 14 generating units and 99 transmission lines. The bus and line data are taken from Tamil Nadu Electricity Board Statistics at a Glance 2003-2004.

Table 4. Total transacted cost for each contract.

\begin{tabular}{lcc}
\hline Transaction & $\begin{array}{c}\text { Transaction cost using } \\
\text { ACPTDF method }(\$ / \mathrm{MW}-\mathrm{h})\end{array}$ & $\begin{array}{c}\text { Transaction cost using } \\
\text { MW-mile method }(\$ / \mathrm{MW}-\mathrm{h})\end{array}$ \\
\hline $\mathrm{T}(1,2,28,25)$ & 25.476 & 25.104 \\
$\mathrm{~T}(2,5,23,50)$ & 121.565 & 128.447 \\
$\mathrm{~T}(3,\{2,11\},\{28,26\}, 30)$ & 156.267 & 157.222 \\
$\mathrm{~T}(4,\{5,13\},\{21,30\}, 25)$ & 137.341 & 139.267 \\
\hline
\end{tabular}




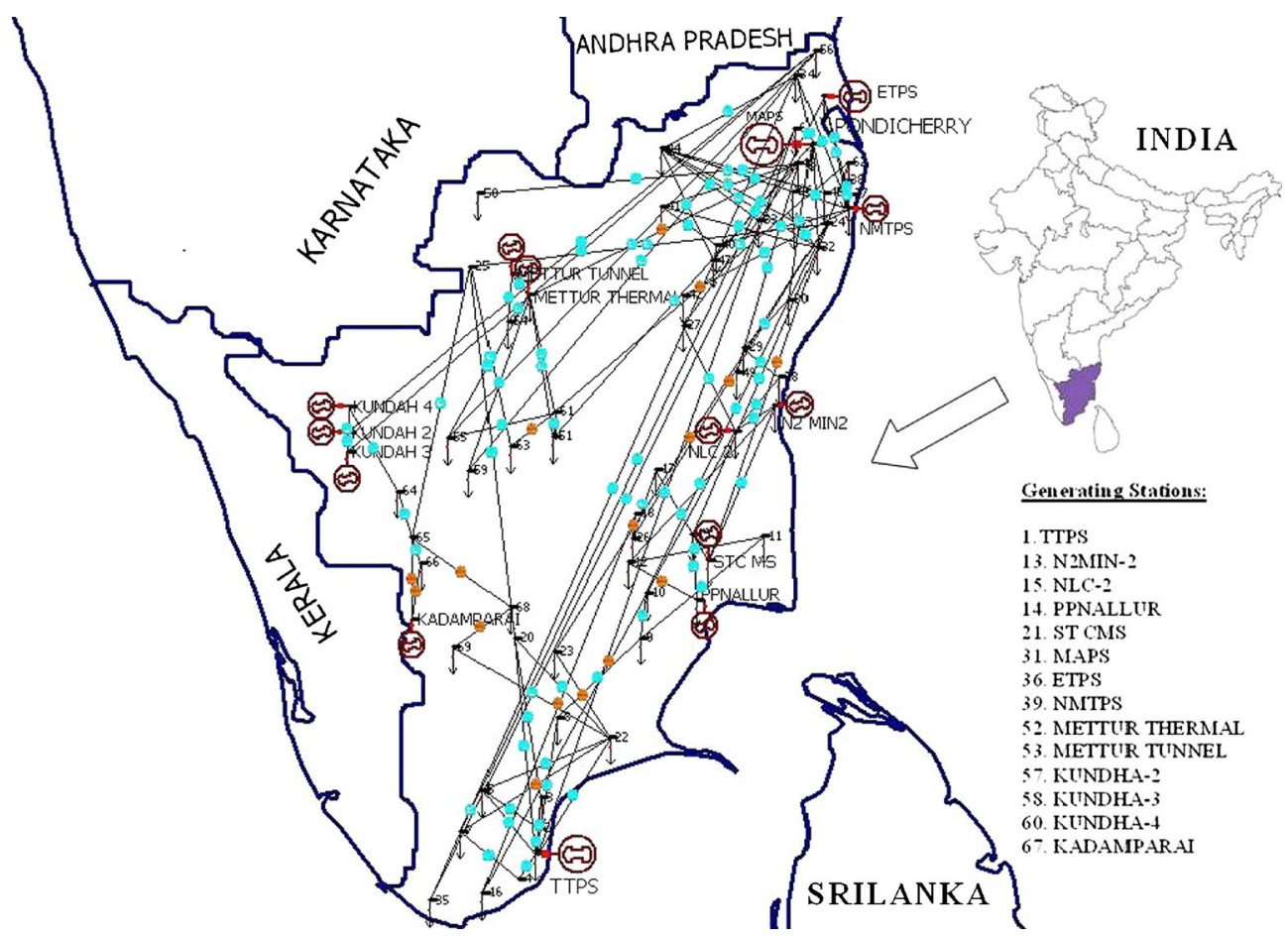

Figure 4. Geographical one line diagram of Indian utility 69 bus system.

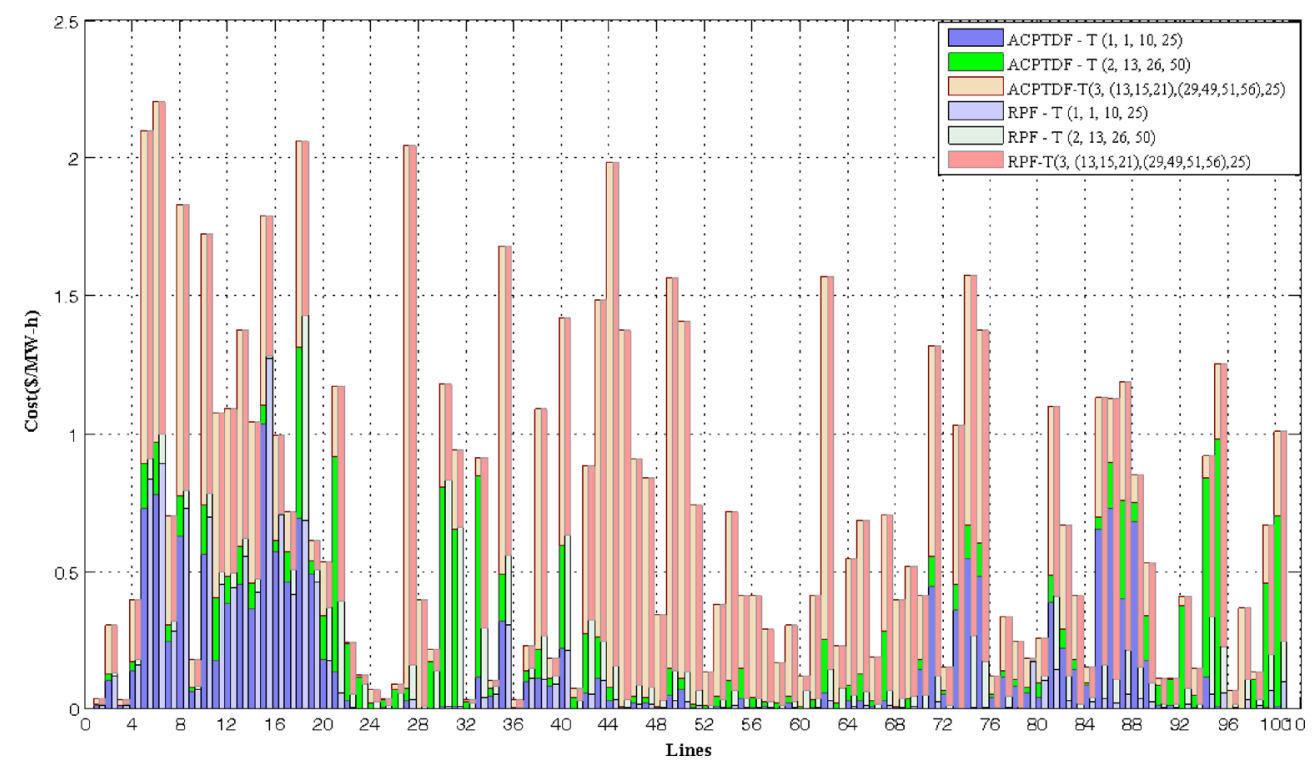

Figure 5. Allocated cost for each line - each contract (\$/MW-h). 
Table 5. Total transacted cost for each contract.

\begin{tabular}{lcc}
\hline Transaction & $\begin{array}{c}\text { Transaction cost using } \\
\text { ACPTDF method }(\$ / M W-h)\end{array}$ & $\begin{array}{c}\text { Transaction cost using } \\
\text { MW-mile method (\$/MW-h) }\end{array}$ \\
\hline $\mathrm{T}(1,1,10,25)$ & 16.004 & 15.034 \\
$\mathrm{~T}(2,13,26,50)$ & 13.735 & 12.452 \\
$\mathrm{~T}(3,\{13,15,21\},\{29,49,51,56\}, 25)$ & 42.385 & 41.637 \\
\hline
\end{tabular}

The geographical one line diagram depicting the utility system is shown in figure 4 . The exact location of buses and generators are incorporated in the network and is drawn using GPS module available with Power World Simulator package (Power World Corporation). In this system, two bilateral transactions such as $\mathrm{T}(1,1,10,25)$ and $\mathrm{T}(2,13,26,50)$ and a multilateral transaction $\mathrm{T}$ $(3,\{13,15,21\},\{29,49,51,56\}, 25)$ are considered. Tuticorin Thermal Power Station (TTPS) is a major generating source and Tamil Nadu state capital, Chennai metropolitan city is a major demand centre in this utility system.

The cost allocation for each line due to various power contracts is shown in figure 5. Normally, the cost allocation for each line is marginally low in the case of two bilateral contracts and it is marginally high in the case of multilateral contract. It is clearly depicted in figure 5 . The highest allocated cost is $2.2 \$ / \mathrm{MW}$-h from the line $1-22\left(6^{\text {th }}\right.$ line $)$, which is connected between TTPS (southern major power source point) and Madurai (middle major power demand point). This is because of the high power impact and moderate transmission cost in that line 1-22. The lowest allocated cost is 0.035 \$/MW-h from the line connected between Samayapuram and Trichy (18$26,32^{\text {nd }}$ line) due to low transmission cost. So, the proposed method predicted the sensitivity of power flows accurately in all lines for various transactions and it has allocated the transaction cost accurately for each line due to each transaction.

The total transacted cost for each contract is given in table 5. The second bilateral contract $\mathrm{T}$ $(2,13,26,50)$ is considered between N2MIN2 and Trichy. Since the distance between the seller and buyer is less, only $13.735 \$ / \mathrm{MW}-\mathrm{h}$ is allocated as transmission cost. As the power impact on transmission lines are evenly distributed and many lines have more transacted power for the multilateral contract $\mathrm{T}(3,\{13,15,21\},\{29,49,51,56\}, 25)$, the allocated cost is higher than other transaction considered.

\section{Conclusion}

The new ACPTDF sensitivity factor approach is a simple and non iterative approach for allocating transmission transaction charges among users in transmission services for various contracts. The change in power flow due to transaction is calculated based on the ACPTDF and the transmission tariff has been calculated based upon it. This method has been applied to sample 6 bus, IEEE 30 bus and practical TNEB 69 bus systems under deregulated environment. This method could be used to resolve some of the difficult pricing and costing issues which arise from the introduction of competition in the electricity 
supply industry and to ensure fairness and transparency in the operation of the transmission system.

\section{Acknowledgements}

This work was supported in part by the University Grants Commission (UGC)-Major Research Project scheme of Government of India (UGC-F. No. 38-244/2009 (SR) dated 24-12-2009).

\section{Appendix A}

Flow chart for the computation of transmission charges.

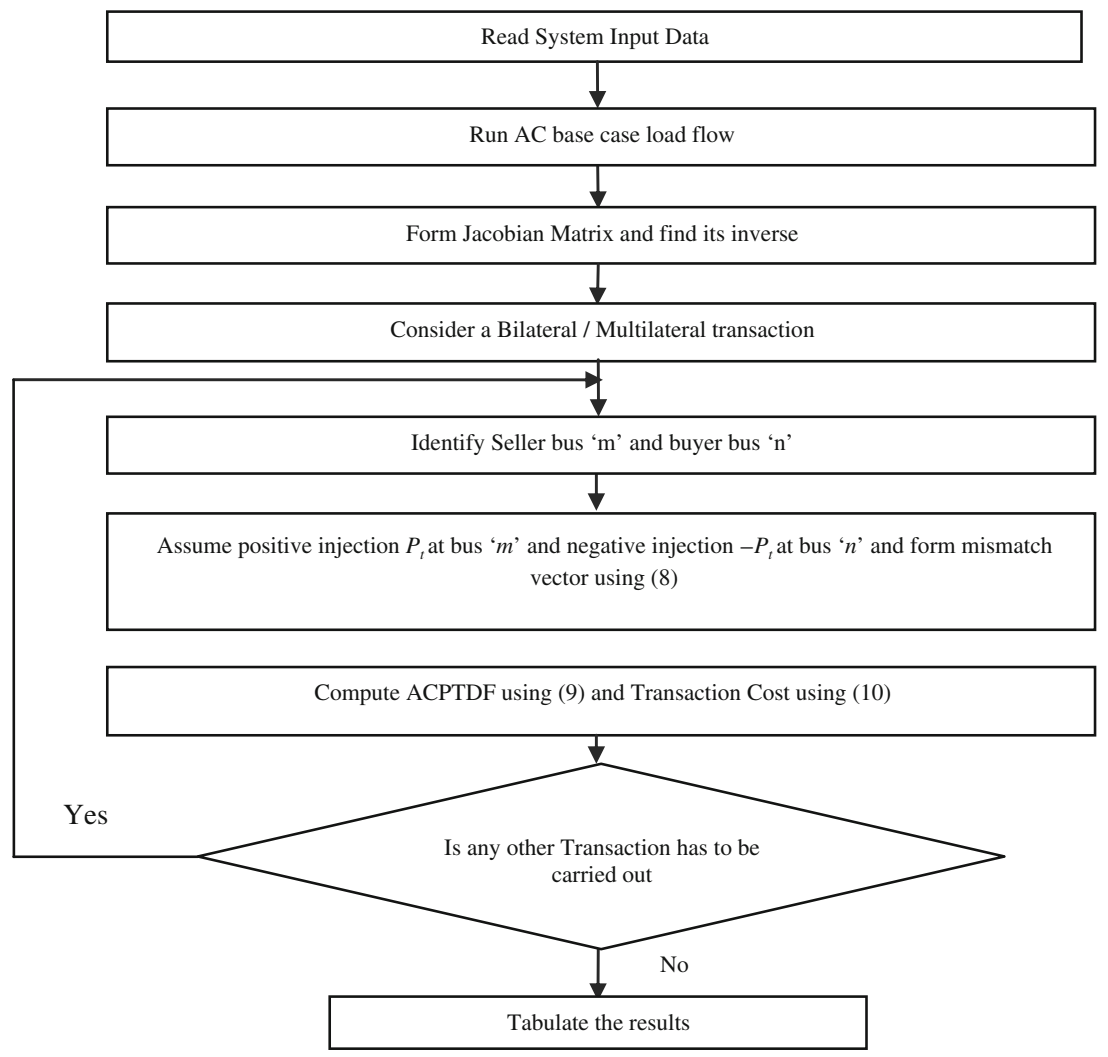




\section{Appendix B}

The line parameters of sample 6 bus system.

\begin{tabular}{ccc}
\hline Line & $\mathrm{R}(\Omega)$ & $\mathrm{X}(\Omega)$ \\
\hline $1-2$ & 0.10 & 0.2 \\
$1-4$ & 0.05 & 0.2 \\
$1-5$ & 0.08 & 0.30 \\
$2-3$ & 0.05 & 0.25 \\
$2-4$ & 0.05 & 0.10 \\
$2-5$ & 0.10 & 0.30 \\
$2-6$ & 0.07 & 0.2 \\
$3-5$ & 0.12 & 0.26 \\
$3-6$ & 0.02 & 0.10 \\
$4-5$ & 0.20 & 0.40 \\
$5-6$ & 0.10 & 0.30 \\
\hline
\end{tabular}

\section{References}

Ashwani Kumar and Srivastava S C 2002 AC Power Distribution Factors for allocating power transactions in a deregulated market. IEEE Power Eng. Rev. 22(7): 42-43

Bialek J 1997 Topological generation and load distribution factors for supplement charge allocation in transmission open access. IEEE Trans. Power Syst. 12(3): 1185-1193

Christie R D, Wollenberg B and Wangensteen I 2000 Transmission management in the deregulated environment. Proc. IEEE 88(2): 170-195

Kirschen D, Allan R and Strback G 1997 Contribution of individual generations to loads and line flows. IEEE Trans. PWRS, 12(1): 52-60

Manikandan B V, Charles Raja S, Venkatesh P and Kannan P S 2008 Available Transfer Capability Determination in the Restructured Electricity Market. Electric Power Components and System 36(9): 941959

NERC 1997 Interconnected operation services working group (IOSWG), Defining Interconnected Operation Services under open access, Final Report, March 7

Ni Y X, Wei P and Wu F F 2000 Power transfer allocation for open access using graph theory, fundamentals and applications in systems without loop flow. IEEE Trans. PWRS 15(3): 923-929

Power World Corporation, http://www.powerworld.com

Shirmohmmadi D, Rajagopalan Ch, Alward E R and Thomas E L 1991 Cost of transmission transactions: an introduction. IEEE Trans. Power Syst. 6(3): 1543-1560

Tamilnadu Electricity Board Statistics at a Glance 2003-2004 Planning Wing of Tamilnadu Electricity Board report, Chennai, India

Willis L, Finney J and Raman J 1996 Computing the cost of unbundled services. IEEE Comput. Appl. Power 9(4): 16-21

Wood A J and Wollenberg B F 1996 Power generation operation and control, New York: John Wiley \& Sons, pp. 416-436 